\title{
EVALUASI KESESUAIAN PASAR RAKYAT KABUPATEN BOGOR BERBASIS KEBUTUHAN PENGGUNA
}

\section{Evaluation of Traditional Market Suitabilities in Kab. Bogor Based on User Needs}

\author{
Luksi Paryatno ${ }^{1}$, Ernan Rustiadi ${ }^{2}$, Netti Tinaprilla ${ }^{3}$ \\ ${ }^{1}$ Program Studi IImu Perencanaan Wilayah, Pascasarjana, Institut Pertanian Bogor, Indonesia \\ ${ }^{2}$ Departemen IImu Tanah, Fakultas Pertanian, Institut Pertanian Bogor, Indonesia \\ ${ }^{3}$ Departemen Agribisnis, Fakultas Ekonomi dan Manajemen, Institut Pertanian Bogor \\ Jalan Meranti, Kampus IPB Darmaga, Bogor, 16680, Jawa Barat, Indonesia \\ Email: Iparyatno@gmail.com
}

Naskah diterima: 20/12/2019; Naskah direvisi: 23/02/2020; Disetujui diterbitkan: 14/05/2020; Dipublikasikan online: 18/12/2020

\begin{abstract}
Abstrak
Pasar rakyat merupakan salah satu sumber Pendapatan Asli Daerah (PAD) di Kabupaten Bogor. Pembangunan pasar mengacu pada Perda Kota Bogor No.11 Tahun 2012 dengan memperhatikan kebutuhan masyarakat di sekitarnya supaya dapat dimanfaatkan secara optimal. Penelitian ini bertujuan untuk melihat kesesuaian kondisi pasar rakyat dengan SNI pasar dan kebutuhan penggunanya. Fasilitas yang dievalusi yaitu sarana prasarana, kebersihan, keamanan, dan aksesibilitas dengan analisis deskriptif terhadap persentase kesesuaian kondisi eksisting dengan SNI pasar. Metode Important Performance Analysis (IPA) digunakan untuk mengukur indeks kepentingan dan kinerja fasilitas pasar serta metode Customer Satisfaction Index (CSI) untuk mengukur indeks kepuasan pengguna terhadap pasar. Hasil penelitian menunjukkan bahwa belum ada pasar yang $100 \%$ sesuai dengan SNI Pasar Rakyat. Berdasarkan persepsi pengguna, terdapat 4 fasilitas penting yang harus diperhatikan pengelola yaitu jumlah hidran air, lokasi hidran air, jumlah CCTV, dan lokasi CCTV. Masih diperlukan kebijakan dalam pengelolaan dan perbaikan pada fasilitas yang tersedia di sebagian besar pasar rakyat yang ada di Kabupaten Bogor, dimana secara keseluruhan tingkat kepuasan pengguna terhadap pasar rakyat kelas I dan kelas II masuk pada kriteria cause for concern dan pada pasar kelas III masuk pada kriteria poor dengan rata-rata kepuasan secara keseluruhan pasar sebesar $70 \%$.
\end{abstract}

Kata Kunci: Pasar Rakyat, Analisis Kepentingan, Tingkat Kepuasan, IPA dan CSI, SNI

\begin{abstract}
Traditional market is one of revenue source (PAD) in Kabupaten Bogor. The market development must refer to Bogor local government regulation No. 11 Tahun 2012 and incorporate the needs of society around them to be optimize maximally. This study aims to find the consistency of the traditional market condition against SNI on market and the needs of the users. The evaluated facilities are the condition of infrastructure, cleanliness, security, and accessibility. Analysis using have been carried out with a method of descriptive heading for measuring the percentage of the consistency of the exsisting traditional market condition with SNI Pasar. A method of Important Performance Analysis (IPA) used to measure performance index of interest and facilities as wel as a method of customer satisfaction index (CSI) for measuring user satisfaction index to the traditional market. The results showed that there was no market that was $100 \%$ in accordance with the SNI Pasar Rakyat. Based on the users perception, there are 4 important facilities that must be considered which are the number of water hydrants, the location of water hydrants, the number of CCTVs, and the location of
\end{abstract}


CCTV. Therefore, market management policy is still needed to improve management and facilities at traditional market in Kabupaten Bogor, where overall user satisfaction to the market class I and class II in on the cause for concern and on class III markets enters at the poor overall satisfaction with an average of $70 \%$.

Keywords: Traditional Market, Performance Analysis, Customer Satisfaction, IPA and CSI, SNI

JEL Classification: F12, F13, F1

\section{PENDAHULUAN}

Pasar tradisional merupakan salah satu pondasi yang memberikan kontribusi dalam pertumbuhan ekonomi nasional. Sebagian besar masyarakat mencari pendapatan dan juga kebutuhan hidup dengan melakukan transaksi jual beli di pasar tradisional. Pasar tradisional di suatu daerah merupakan indikator yang paling nyata untuk melihat kegiatan perekonomian masyarakat (Adiyadnya 2015; Triatmojo 2019) dan mengukur pertumbuhan serta dinamika ekonomi suatu daerah. Tingginya aktivitas di pasar merupakan salah satu indikator dinamisnya perputaran roda perekonomian daerah.

Definisi pasar tradisional diatur dalam Peraturan Presiden No. 112 Tahun 2007 yang kemudian diubah menjadi pasar rakyat sesuai UU No.7 Tahun 2014 tentang perdagangan. Berdasarkan PerMendag No. 61/MDAG/PER/8/2015 tentang pedoman pembangunan pasar, pasar rakyat adalah pasar yang dibangun dan dikelola oleh Pemerintah, Pemerintah
Daerah, Swasta, Badan Usaha Milik Negara dan Badan Usaha Milik Daerah termasuk kerja sama dengan swasta dengan tempat usaha berupa toko, kios, los, dan tenda yang dimiliki/dikelola oleh pedagang kecil, menengah, swadaya masyarakat atau koperasi dengan usaha skala kecil, modal kecil, dan dengan proses jual beli barang dagangan melalui tawar menawar. Selanjutnya, dalam rangka penataan lokasi pasar, Pemerintah mengeluarkan Permendagri No. 20 Tahun 2012 tentang pengelolaan dan pemberdayaan pasar tradisional yang menyatakan pasar rakyat berlokasi pada setiap sistem jaringan jalan, termasuk sistem jaringan jalan lokal atau jalan lingkungan pada kawasan pelayanan bagian kota/kabupaten atau lokal atau lingkungan (perumahan) di dalam kota/kabupaten.

Berbagai kebijakan terkait
penataan dan pemberdayaan pasar
belum dapat diimplementasikan secara
optimal, hal ini terlihat dari sebagian
pasar yang telah beroperasi masih


memerlukan perbaikan dalam hal pembangunan dan pengelolaan. Beberapa penelitian yang dilakukan terkait pasar rakyat di berbagai daerah telah dilakukan antara lain pada pasar di wilayah Kota Surakarta (Nida, 2014), Pasar Bulu Semarang (Dwirahayu., et al, 2015), Pasar Cipulir Jakarta (Anggraini \& Susetyo, 2016), Pasar Besuki Tulungagung (Minarni \& Nurhadi, 2016), Pasar Peterongan Semarang (Adeliana, 2017), dan Pasar di wilayah Kabupaten Badung (Stutiari, 2019). Evaluasi juga dilakukan Pemerintah Daerah oleh dinas terkait seperti di Kalimantan Selatan. Hasil yang diperoleh menunjukkan dimana kondisi pasar rakyat masih memerlukan peningkatan fasilitas dan pelayanan agar pasar dapat berfungsi secara maksimal.

Pengelolaan pasar rakyat yang baik perlu mengacu pada standar, sehingga mekanisme pengelolaan dan upaya untuk melakukan perlindungan konsumen tercapai. Standar yang diacu untuk pedoman dalam membangun dan mengelola pasar rakyat, serta memberdayakan komunitas pasar adalah Standar Nasional Indonesia (SNI) Nomor 8152 tahun 2015 tentang pasar rakyat. SNI 8152:2015 ditetapkan oleh Badan Standarisasi Nasional (BSN) dan berlaku di wilayah Negara
Kesatuan Republik Indonesia (NKRI) terkait pasar dengan lokasi tetap.

Latar belakang kebijakan SNI 8152:2015 disusun, antara lain adalah karena tuntutan pengguna terhadap pasar yang sudah relatif tinggi dari sisi kebersihan, tertib ukur dan niaga serta kenyamanan bertransaksi dengan menghilangkan kesan kumuh untuk memudahkan para pelaku pasar dalam membangun dan mengelola pasar. Dengan demikian pasar rakyat dikelola secara professional menjadi sarana yang kompetitif terhadap pusat perbelanjaan, pertokoan maupun pusat perdagangan lainnya serta meningkatkan perlindungan terhadap konsumen (UU Nomor 8 Tahun 1999). Hal ini sejalan dengan penelitian Qoriah (2014) yang menyatakan bahwa untuk mempertahankan eksistensi pasar perlu dilakukan pembangunan pasar dengan memperhatikan bentuk bangunan, penataan zonasi, jumlah pedagang, fasilitas, lokasi dan aksesibilitas pasar.

Pasar rakyat merupakan salah satu sumber Pendapatan Asli Daerah (PAD) di Kabupaten Bogor. Dalam menunjang fungsi pasar tersebut, pemerintah daerah mengeluarkan Perda No. 11 Tahun 2012 dimana pembangunan pasar harus mengacu pada ketentuan yang berlaku dan 
memperhatikan kebutuhan masyarakat disekitarnya. Proses pembangunan pasar merupakan hasil kesepakatan dengan beberapa pihak terutama pedagang (Magdina, 2018). Saat ini pasar rakyat yang telah dibangun di Kabupaten Bogor kurang dimanfaatkan secara optimal untuk melakukan transaksi perdagangan. Bangunan fisik maupun fasilitas yang tersedia pada sebagian besar pasar rakyat masih belum sesuai dengan SNI pasar. Pembangunan dan penentuan kelas pasar hanya berdasarkan pada ketersediaan lahan yang dapat digunakan, belum dilakukan prosedur kajian dalam menentukan lokasi dan kelas pasar yang sesuai. Kios/los yang dimanfaatkan oleh pedagang hanya sebagian kecil dari jumlah kios/los yang tersedia di setiap pasar. Di Pasar Leuwiliang, dari $1.231 \mathrm{kios} / \mathrm{los}$ yang tersedia hanya 785 yang digunakan untuk berdagang. Selain itu, di Pasar Cileungsi masih terdapat 748 kios yang tutup atau tidak digunakan. Kondisi terparah terjadi di Pasar Parung dimana hanya 910 kios/los yang digunakan oleh pedagang dari 2.156 kios/los yang tersedia di pasar. Ini mengindikasikan fungsi pasar belum optimal dalam menunjang perekonomian daerah khususnya sektor perdagangan.

Berdasarkan hal di atas maka penelitian ini bertujuan untuk mengevaluasi sejauh mana Kesesuaian kondisi Pasar Rakyat di Kabupaten Bogor dengan SNI Pasar Rakyat serta Kebutuhan Pengguna Pasar yaitu pedagang dan pembeli.

\section{METODE}

Data yang digunakan dalam penelitian ini adalah data primer yang diperoleh langsung melalui wawancara dengan pengelola pasar dan kuesioner yang diberikan kepada pengguna pasar, yaitu pedagang maupun pembeli di 27 pasar rakyat Kabupaten Bogor.

Variabel yang digunakan untuk mengevaluasi kondisi pasar rakyat adalah: 1) Kesesuaian kondisi fisik dan fasilitas, 2) Kebersihan area pasar, 3) Keamanan di area pasar, dan 4) Aksesibilitas menuju dan yang ada di pasar. Variabel dan indikator yang akan diukur dapat dilihat pada Tabel 1. 
Tabel 1. Variabel dan Indikator

\begin{tabular}{|c|c|c|}
\hline No & Variabel & Indikator \\
\hline 1 & $\begin{array}{l}\text { Kesesuaian } \\
\text { sarana dan } \\
\text { prasarana }\end{array}$ & $\begin{array}{ll}\text { a. } & \text { Ukuran kios/los } \\
\text { b. } & \text { Area/zonasi } \\
\text { c. } & \text { Jumlah Fasilitas } \\
& \text { yang tersedia (toilet } \\
& \text { dan kamar mandi } \\
\text { d. } & \text { Pos ukur ulang } \\
\text { e. } & \text { Hidran air } \\
\text { f. } & \text { Jumlah pengelola } \\
\text { g. } & \text { Lahan parkir }\end{array}$ \\
\hline 2. & Kebersihan & $\begin{array}{l}\text { a. Tempat sampah } \\
\text { b. Jadwal } \\
\text { pengangkutan } \\
\text { sampah } \\
\text { c. Tempat } \\
\text { pembuangan } \\
\text { sampah sementara } \\
\end{array}$ \\
\hline 3. & Keamanan & $\begin{array}{l}\text { a. Jumlah dan lokasi } \\
\text { CCTV } \\
\text { b. Pos Keamanan }\end{array}$ \\
\hline 4. & Aksesibilitas & $\begin{array}{ll}\text { a. } & \text { Jarak dari } \\
& \text { Pemukiman } \\
\text { b. } & \text { Biaya transportasi } \\
\text { menuju pasar } \\
\text { c. Lebar } \\
\text { koridor/gangway } \\
\text { d. } \\
\text { Akses untuk korsi } \\
\text { roda }\end{array}$ \\
\hline
\end{tabular}

\section{Responden Penelitian}

Responden penelitian ini adalah pengelola pada 27 pasar rakyat (Table 2) di Kabupaten Bogor yang terdiri dari Kelas I, Kelas II, dan Kelas III, serta pengguna pasar rakyat sebanyak 270 orang yang terdiri dari lima pembeli dan lima pedagang yang mewakili setiap komoditas (sayur, buah, ikan, daging dan bahan pokok). Metode yang digunakan adalah metode wawancara dan mengisi kuesioner terkait data kondisi eksisting pasar.
Tabel 2. Daftar Nama Pasar Rakyat

\begin{tabular}{|c|c|c|}
\hline No & $\begin{array}{l}\text { Kelas } \\
\text { Pasar }\end{array}$ & Nama Pasar \\
\hline 1 & $\begin{array}{l}\text { Pasar } \\
\text { Kelas I }\end{array}$ & $\begin{array}{ll}\text { 1. } & \text { Pasar Cileungsi } \\
\text { 2. } & \text { Pasar Cibinong } \\
\text { 3. } & \text { Pasar Citeureup I } \\
\text { 4. } & \text { Pasar Citeureup II } \\
\text { 5. } & \text { Pasar Parung } \\
\text { 6. } & \text { Pasar Jonggol } \\
\text { 7. } & \text { Pasar Cisarua } \\
\text { 8. } & \text { Pasar Cariu } \\
\text { 9. } & \text { Pasar Ciluar/Sukaraja } \\
\text { 10. } & \text { Pasar Parung Panjang } \\
\text { 11. } & \text { Pasar Leuwiliang } \\
\text { 12. } & \text { Pasar Laladon/Ciomas }\end{array}$ \\
\hline 2 & $\begin{array}{l}\text { Pasar } \\
\text { Kelas II }\end{array}$ & $\begin{array}{l}\text { 13. Pasar Ciawi } \\
\text { 14. Pasar Jasinga } \\
\text { 15. Pasar Cigombong } \\
\text { 16. Pasar Cicangkal/Rumpin } \\
\text { 17. Pasar Citayam/Bojong } \\
\text { gede } \\
\text { 18. Pasar Cigudeg }\end{array}$ \\
\hline 3 & $\begin{array}{l}\text { Pasar } \\
\text { Kelas } \\
\text { III }\end{array}$ & $\begin{array}{l}\text { 19. Pasar Ciseeng } \\
\text { 20. Pasar } \\
\text { Parungpung/Gunung } \\
\text { Sindur } \\
\text { 21. Pasar Cikereteg/ } \\
\text { Caringin } \\
\text { 22. Pasar Kemang } \\
\text { 23. Pasar Tenjo } \\
\text { 24. Pasar Nanggung } \\
\text { 25. Pasar Taman Sari } \\
\text { 26. Pasar Cijeruk } \\
\text { 27. Pasar Babakan Madang }\end{array}$ \\
\hline
\end{tabular}

\section{Teknik Analisis}

\section{Kesesuaian Kondisi Pasar Rakyat dengan SNI Pasar}

Analisis yang dilakukan adalah dengan membandingkan antara kondisi eksisting setiap pasar dengan standar yang ada dalam SNI Pasar berdasarkan ukuran, jumlah dan lokasi dari setiap fasilitas. Selanjutnya, direkapitulasi persentase kesesuaian secara keseluruhan pada setiap pasar rakyat 
dengan melihat hasil dari setiap fasilitas yang dinilai.

\section{Kesesuaian Pasar Rakyat dengan Kebutuhan Pengguna Pasar}

Data yang diperoleh diolah dengan metode IPA (Important Performance Analysis) untuk mengetahui kepuasan pengguna pasar rakyat akan fasilitas yang tersedia dan CSI (Customer Satisfaction Index) untuk mengetahui tingkat kepuasan pengguna pasar secara menyeluruh terhadap kinerja setiap fasilitas di pasar rakyat. IPA adalah suatu teknik analisis yang digunakan untuk mengidentifikasi faktor-faktor penting apa saja yang harus ditampilkan oleh suatu organisasi dalam memenuhi kepuasan para pengguna jasa/konsumen (Umam \& Hariastuti, 2018). CSI digunakan untuk mengetahui tingkat kepuasan pengguna jasa secara menyeluruh dengan melihat tingkat kinerja dan tingkat kepentingan/ harapan dari atribut-atribut jasa pelayanan (Sumaga, 2013).

Metode IPA dan CSI ini sudah pernah dilaksanakan oleh (Mattanete, 2008) untuk menilai kepuasan pedagang terhadap pengelolaan pasar Citeureup I, (Handriati, Sunaryo, \& Helia, 2015) untuk menilai kepuasan terhadap fasilitas terminal, (Anggraini, Deoranto, \& Ikasari, 2015) menilai kepuasan café \& resto, dan (Umam \& Hariastuti, 2018) dalam menilai kepuasan pelanggan OIS Photography.

\section{a) Importance}

Performance

\section{Analysis (IPA)}

Matriks IPA memiliki dua dimensi, $X$ dan $Y$. Sumbu $X$ menunjukkan kepuasan pengguna pasar terhadap fasilitas sarana prasarana yang tersedia, sedangkan sumbu $Y$ menunjukkan penilaian tingkat kepentingan fasilitas sarana prasarana menurut pengguna pasar. Matriks ini sangat bermanfaat sebagai pedoman dalam mengalokasikan fasilitas sarana prasarana yang dibutuhkan dan dimana perbaikan yang perlu dilakukan yang berdampak besar pada kepuasan pengguna pasar secara total. Selain itu, matriks ini juga menunjukkan fasilitas sarana prasarana yang perlu dipertahankan karena sudah sesuai dan fasilitas sarana prasarana yang perlu dikurangi prioritasnya.

Angka kepuasan/kepentingan fasilitas sarana prasarana menurut pengguna pasar adalah:

$S Q_{i}=\frac{1}{m} \sum_{j=1} k P S_{i j}$

diketahui:

$\mathrm{SQ}_{i}$ : Angka tingkat kepuasan/ kepentingan untuk atribut ke-i 
PS $S_{i j}$ : Total nilai jawaban responden tingkat kepuasan/kepentingan untuk atribut ke-i

M : Total responden

K : Jumlah atribut pertanyaan

Hasil analisis yang diperoleh menunjukkan posisi kuadran dari setiap fasilitas berdasarkan tingkat kepentingan dan kepuasan pengguna pasar, yang akan ditampilkan dalam kuadran IPA seperti pada Gambar 1.

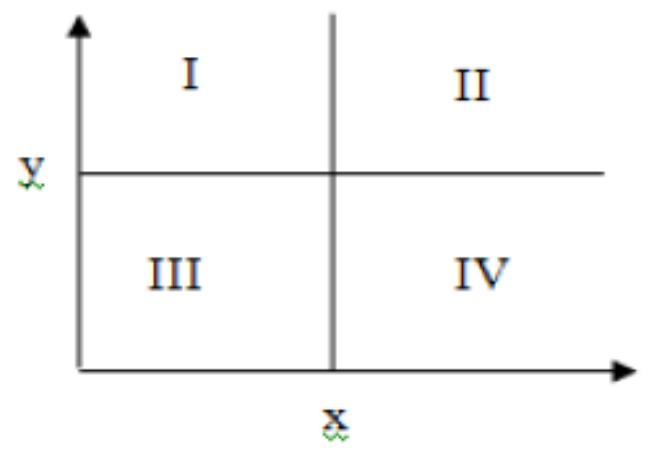

\section{Gambar 1. Kuadran IPA}

(a) Kuadran I (Concentrate These)

Wilayah ini memuat fasilitas yang dianggap penting oleh pengguna, tetapi pada kenyataannya fasilitas ini belum sesuai dengan harapan pengguna (tingkat kepuasan yang diperoleh masih rendah). Variabel-variabel yang masuk dalam kuadran ini harus ditingkatkan.

(b) Kuadran II (Keep Up The Good Work)

Wilayah ini memuat fasilitas yang dianggap penting oleh pengguna pasar dan fasilitas yang dianggap pengguna pasar sudah sesuai dengan yang dirasakannya sehingga tingkat kepuasannya relatif lebih tinggi. Fasilitas yang masuk dalam kuadran ini harus tetap dipertahankan karena fasilitas ini yang merupakan fasilitas yang unggul dimata pengguna pasar.

(c) Kuadran III (Low Priority)

Wilayah ini memuat fasilitas yang dianggap kurang penting oleh pengguna pasar, dan pada kenyataannya kondisi yang ada tidak terlalu istimewa. Peningkatan yang dilakukan terhadap fasilitas di kuadran ini dapat dipertimbangkan kembali karena pengaruh terhadap manfaat yang dirasakan pengguna pasar sangat kecil.

(d) Kuadran IV (Possible Overkil)

Wilayah ini memuat fasilitas yang dianggap kurang penting oleh pengguna pasar dan dirasakan terlalu berlebihan. Fasilitas yang termasuk dalam kuadran ini dapat dihilangkan untuk efisiensi.

\section{b) Customer Satisfaction Index (CSI)}

Customer Satisfaction Index (CSI) digunakan untuk mengetahui tingkat kepuasan pengguna pasar secara menyeluruh dengan melihat tingkat kepuasan dari kinerja setiap fasilitas yang tersedia di pasar. Besarnya CSI dapat diketahui dengan langkahlangkah sebagai berikut: 
(a) Menentukan Mean Importance Score (MIS) tiap-tiap atribut, nilai ini berasal dari rata-rata kepentingan atribut fasilitas sarana prasarana dari tiap pengguna pasar rakyat dengan rumus:

$M I S=\frac{\sum_{i=1}^{n} Y i}{n}$

diketahui:

$\mathrm{N}$ : Jumlah responden

$Y_{i}$ : Nilai kepentingan atribut $Y$ ke-i

(b) Membuat Weight Factors (WF) per atribut. Bobot ini merupakan prosentase nilai MIS per atribut terhadap total MIS seluruh atribut dengan rumus:

$W F=\frac{M I S i}{\sum_{i=1}^{p} M I S i} \times 100 \%$

diketahui:

I : Atribut kepentingan ke-i

(c) Menentukan Mean Performance Score (MPS) tiap atribut.

$M P S=\frac{\sum_{i=1}^{n} X i}{n}$

(d) Membuat Weight Score (WSi) tiap atribut. Bobot ini merupakan perkalian antara $\mathrm{WF}_{i}$ dengan $\mathrm{MPS} \mathrm{S}_{i}$ dengan rumus:

$$
W S i=W F i x M P S
$$

(e) Menghitung Customer Satisfaction Index, yaitu Weight Total (WT) dibagi skala maksimum yang digunakan, kemudian dikalikan 100\%. Tingkat kepuasan responden secara keseluruhan dapat dilihat dari kriteria tingkat kepuasan.

$C S I=\frac{\sum_{i=1}^{p} W S i}{H S} \times 100 \%$

diketahui:

$\begin{aligned} & \text { CSI }: \text { Customer Satisfaction } \\ & \text { Index (\%) } \\ & \mathrm{WS}_{\mathrm{i}}: \text { Weight Score } \\ & \mathrm{I}: \text { Atribut kepentingan ke-i } \\ & \mathrm{HS} \quad: \text { Skala maksimum yang } \\ & \\ & \\ & \text { digunakan }\end{aligned}$

Nilai CSI yang diperoleh dalam penelitian ini dibagi dalam tujuh kriteria penilaian seperti yang dilakukan oleh Handriati (2015) dengan penjelasan rinci seperti dalam Tabel 3.

\section{Tabel 3. Kriteria CSI}

\begin{tabular}{ccc}
\hline No & Nilai Index (\%) & Kriteria CSI \\
\hline 1. & $X \leq 64 \%$ & Very Poor \\
2. & $64 \%<X \leq 71 \%$ & Poor \\
3. & $71 \%<X \leq 77 \%$ & Cause for \\
& & Concern \\
4. & $77 \%<X \leq 80 \%$ & Borderline \\
5. & $80 \%<X \leq 84 \%$ & Good \\
6. & $84 \%<X \leq 87 \%$ & Very Good \\
7. & $87 \%<$ & Excellent \\
\hline
\end{tabular}

\section{HASIL DAN PEMBAHASAN}

Kesesuaian Pasar Rakyat dengan SNI Pasar Rakyat 8152:2015

a) Pasar Kelas I

Secara keseluruhan, kondisi bangunan dan fasilitas yang tersedia di Pasar Rakyat Kelas I di Kabupaten Bogor belum ada yang sesuai secara 100\% dengan SNI Pasar Rakyat seperti 
ditampilkan pada Gambar 2. Pasar dengan kesesuaian tertinggi pertama dengan kriteria SNI Pasar Rakyat adalah Pasar Cibinong, kemudian Pasar Jonggol dan Pasar Cileungsi. Pasar dengan fasilitas yang paling tidak sesuai dengan kriteria SNI Pasar Rakyat adalah Pasar Cisarua dengan persentase 53.33. Rata-rata persentase kesesuaian Pasar Kelas I dengan SNI
Pasar Rakyat adalah sebesar 68,89. Fasilitas yang perlu mendapat perhatian dan menjadi bahan evaluasi pada sebagian besar pasar kelas I adalah ketersediaan pos ukur ulang, hidran air, ruang menyusui, dan akses bagi pengguna kursi roda. Fasilitas-fasilitas tersebut termasuk yang belum tersedia hampir di seluruh Pasar Kelas I di Kabupaten Bogor.

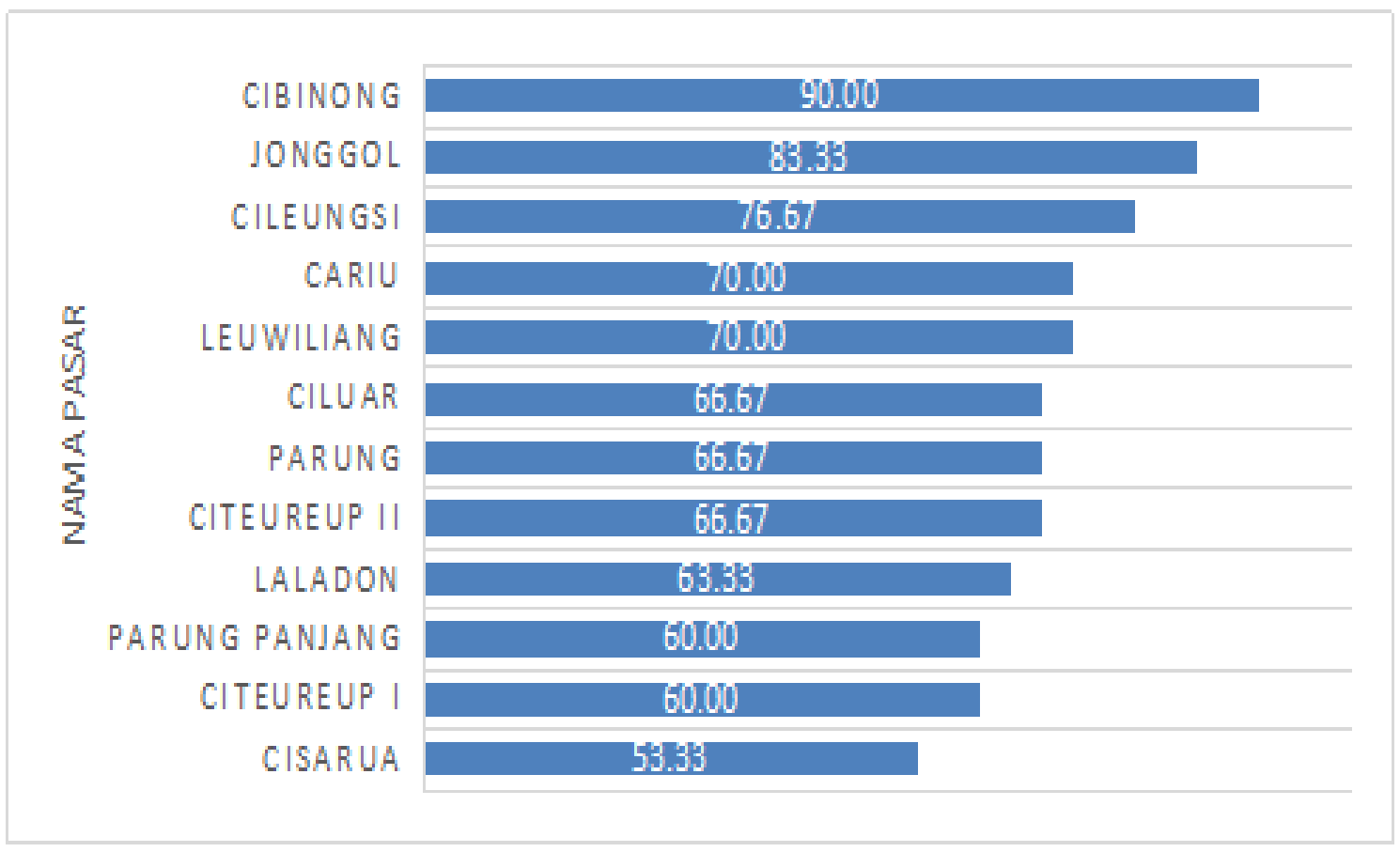

\section{Gambar 2. Persentase Kesesuaian Pasar Kelas I}

b) Pasar Kelas II

Pasar dengan fasilitas yang paling sesuai dengan kriteria SNI untuk Pasar Kelas II seperti yang ditampilkan pada Gambar 3 adalah Pasar Ciawi, selanjutnya adalah Pasar Cigombong. Fasilitas yang perlu mendapat perhatian dan evaluasi adalah ketersediaan fasilitas pos ukur ulang, ruang menyusui, jumlah tempat sampah, dan akses bagi pengguna kursi roda karena fasilitas tersebut tidak tersedia hampir di seluruh Pasar Kelas II. Secara keseluruhan, belum ada Pasar Kelas II yang sesuai 
dengan kriteria SNI Pasar Rakyat rata Pasar Kelas II terhadap SNI Pasar dimana persentase nilai kesesuaian rata- Rakyat adalah sebesar 70,55.

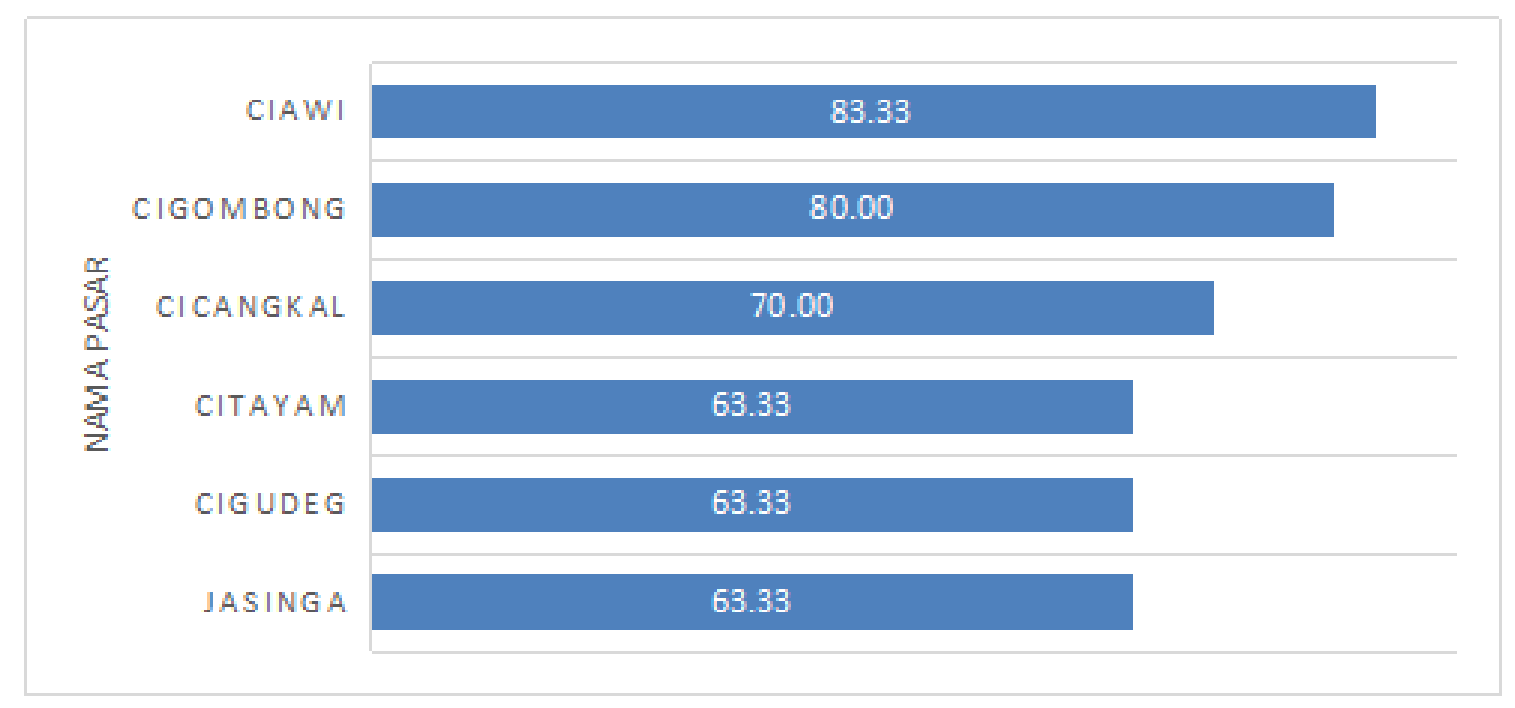

\section{Gambar 3. Persentase Kesesuaian Pasar Kelas II}

c) Pasar Kelas III

Secara keseluruhan, kondisi bangunan dan fasilitas yang tersedia pada Pasar Kelas III Kabupaten Bogor masih belum sesuai dengan kriteria pada SNI Pasar Rakyat (Gambar 4). Pasar Tamansari merupakan Pasar Kelas III dengan tingkat kesesuaian terhadap SNI Pasar Rakyat paling rendah, dengan rata-rata nilai persentase kesesuaian adalah sebesar 62,22, hal ini dikarenakan masih banyak fasilitas yang belum tersedia dan tidak sesuai standar. Fasilitas yang masih perlu untuk mendapat perhatian pada Pasar Kelas III adalah ketersediaan pos ukur ulang, toilet, dan hidran air. Ketiga fasilitas tersebut masih belum tersedia di seluruh Pasar Kelas III di Kabupaten Bogor. 


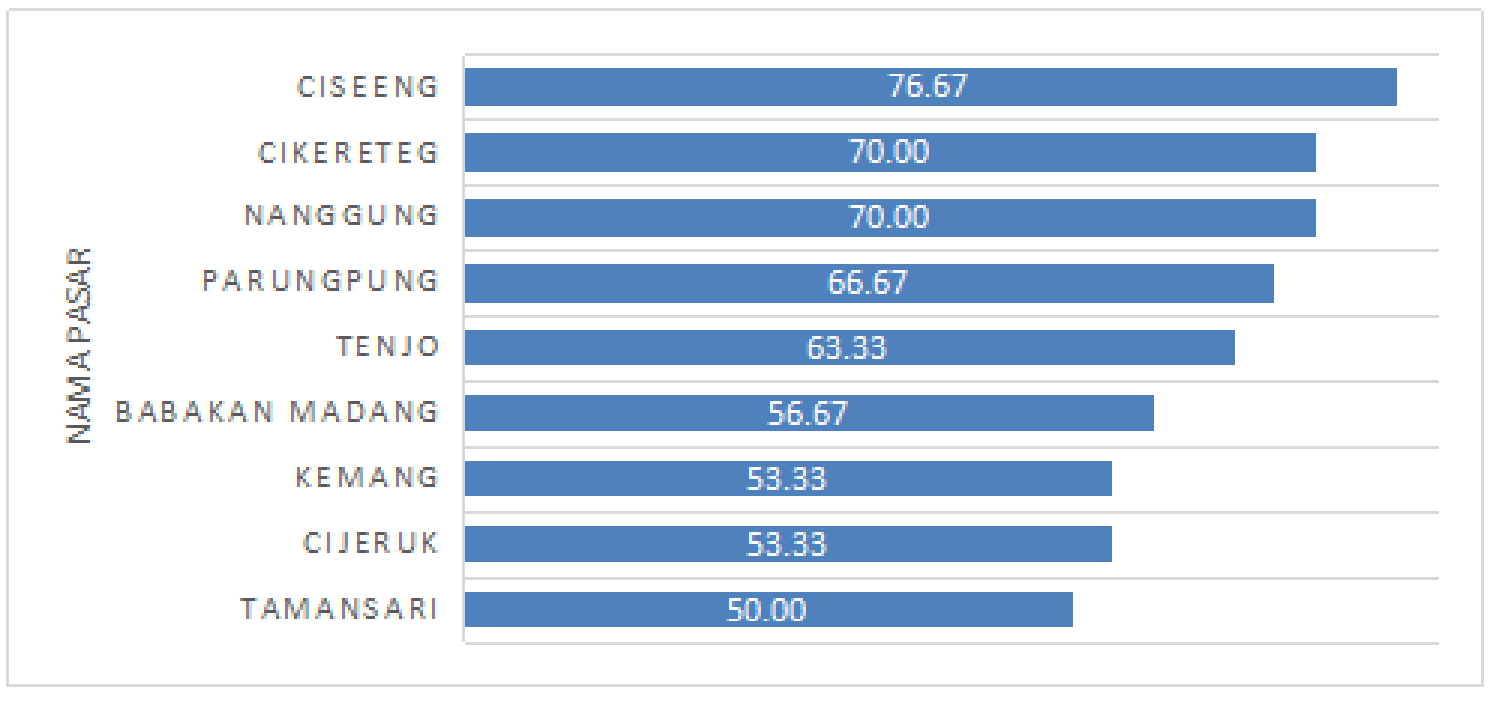

\section{Gambar 4. Persentase Kesesuaian Pasar Kelas III}

Kesesuaian Pasar Rakyat dengan Kebutuhan Pengguna Pasar

Hasil uji validitas product moment menyatakan bahwa semua fasilitas pada instrumen kesesuaian sarana dan prasana, kebersihan pasar rakyat, keamanan pasar rakyat dan aksesibilitas pasar rakyat diperoleh nilai $r$ yang lebih besar dari 0.3 , sehingga dapat disimpulkan bahwa instrumen tersebut dinyatakan valid. Berdasarkan hasil uji reliabilitas alpha Cronbach didapatkan hasil semua variabel yang diukur memperoleh nilai Alpha > 0.6, sehingga dapat disimpulkan bahwa semua instrumen pengukuran dari keseluruhan variabel tersebut telah reliabel.

Terdapat 27 fasilitas yang masuk dalam instrumen survei bagi pengguna pasar untuk analisis IPA dan CSI, yaitu: 1) Lokasi kios/los yang mudah dijangkau, 2) Ukuran luas kios/los, 3) Kios/los sudah dibagi berdasarkan zonasi, 4) Jumlah tempat ibadah, 5) Lokasi tempat ibadah, 6) Jumlah hidran air, 7) Lokasi hidran air, 8) Pos ukur ulang, 9) Harga produk, 10) Kualitas produk, 11) Jumlah tempat sampah, 12) Lokasi tempat sampah, 13) Jadwal pengangkutan sampah, 14) Lokasi TPS, 15) Jumlah toilet/WC, 16) Lokasi toilet/WC, 17) Akses masuk pasar, 18) Rasa aman bertransaksi, 19) Jumlah pos keamanan, 20) Pelayanan petugas keamanan, 21) Jumlah CCTV, 22) Lokasi CCTV, 23) Kondisi area parkir, 24) Lokasi pasar, 25) Alat transportasi umum menuju pasar, 26) Lorong/ gangway, 27) Akses khusus bagi pengguna kursi roda. Hasil yang diperoleh berdasarkan data setiap kelas pasar adalah sebagai berikut: 
a) Pasar Kelas I

Hasil yang diperoleh berdasarkan IPA atau analisis kinerja dan kepentingan pengguna pasar dari 12 Pasar Kelas I di Kabupaten Bogor ditampilkan pada Gambar 5. Dari 27 fasilitas yang dievaluasi, 22 fasilitas masuk kedalam kuadran II yang artinya pengguna pasar menganggap fasilitas ini sangat penting untuk ada di pasar rakyat dan kondisi yang ada saat ini sudah cukup memuaskan. Selain itu terdapat empat fasilitas yang masuk kedalam kuadran I, hal ini berarti fasilitas tersebut dianggap penting oleh pengguna pasar, namun kondisinya masih belum sesuai dengan kebutuhan mereka dan diperlukan perbaikan pada fasilitas-fasilitas tersebut karena merupakan prioritas utama bagi pengguna pasar agar pasar rakyat dapat berjalan lebih optimal.

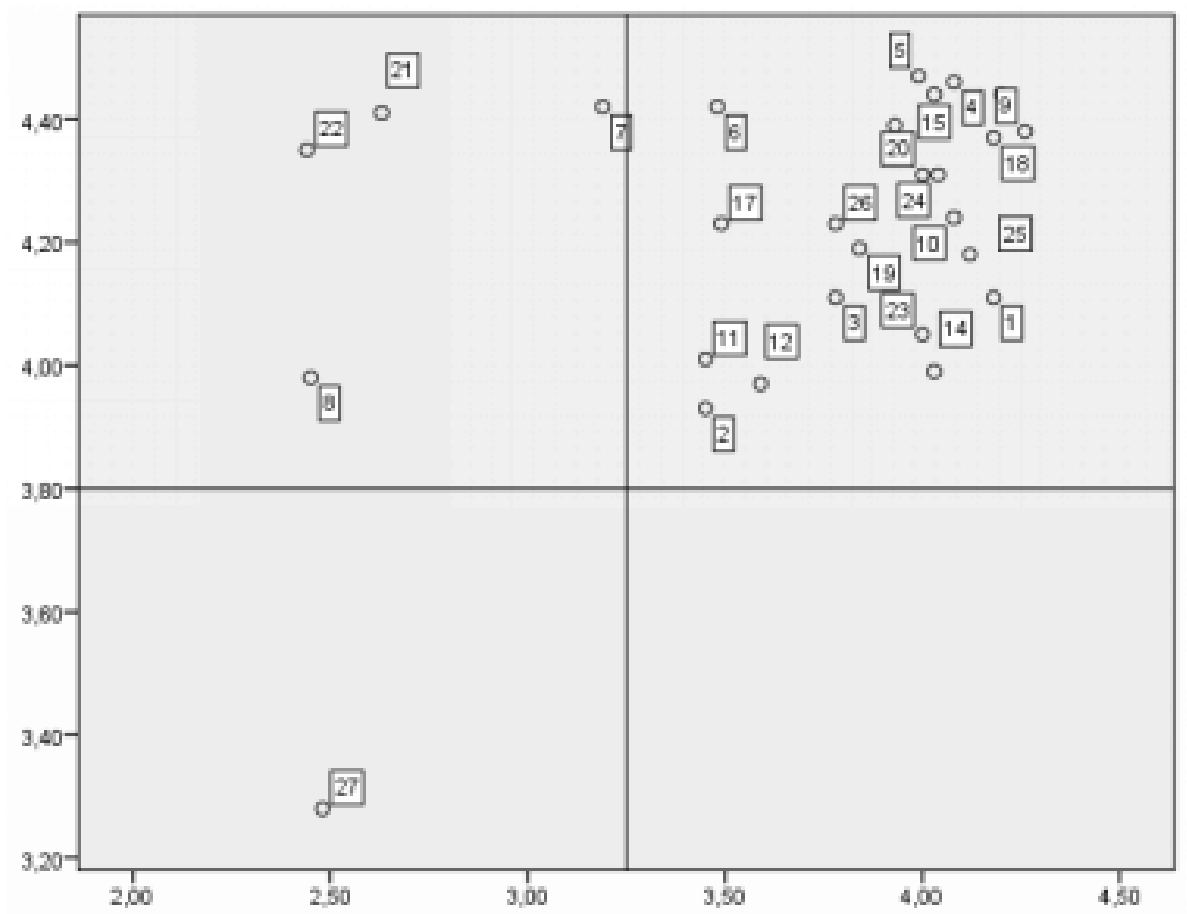

\section{Gambar 5. IPA Pasar Kelas I}

Terdapat satu fasilitas yang masuk kuadran III, yang dianggap tidak begitu penting oleh pengguna pasar dan kondisinya masih kurang memuaskan. Serta pada pasar kelas I tidak ada fasilitas yang masuk kedalam kuadran
IV. Artinya semua fasilitas yang diukur dianggap penting keberadaannya oleh pengguna pasar.

Terdapat empat fasilitas pasar yang belum sesuai dengan kebutuhan pengguna pasar dan masih perlu 
diperbaiki yaitu lokasi hidran air, pos ukur ulang, jumlah CCTV, dan Lokasi CCTV. Semua fasilitas tersebut sudah tersedia di beberapa pasar kelas I, tetapi pengguna pasar menyatakan kondisi yang ada saat ini belum sesuai dengan kebutuhan, baik secara jumlah CCTV dan jumlah pos ukur ulang, maupun secara lokasi penempatan sarana seperti hidran air, pos ukur ulang, dan letak CCTV.

Pos ukur ulang merupakan salah satu sarana perlindungan bagi konsumen yang dalam hal ini adalah pembeli di pasar rakyat. Pos ukur ulang hanya terdapat di Pasar Cariu dan Pasar Cibinong, sedangkan di pasar kelas I lainnya belum tersedia. Untuk fasilitas keamanan berupa CCTV dianggap sangat penting oleh pengguna pasar, namun fasilitas ini belum terdapat di semua pasar kelas I. CCTV baru tersedia di Pasar Cileungsi, Pasar Jonggol, Pasar Cariu, Pasar Ciluar, dan Pasar Cibinong. Selain masih banyak pasar kelas I yang belum memiliki fasilitas CCTV, pada pasar yang telah tersedia, lokasi penempatan CCTV dianggap belum sesuai dengan kebutuhan pengguna.

Salah satu sarana keselamatan yang merupakan prioritas utama bagi pengguna pasar adalah hidran air.
Hidran air yang tersedia di pasar kelas I masih belum sesuai dengan kebutuhan pengguna pasar. Pasar Citeureup I, Pasar Parung Panjang, Pasar Cariu, dan Pasar Cisarua belum menyediakan hidran air sebagai salah satu fasilitas keselamatan. Pasar kelas I lainnya sudah tersedia hidran air, namun jumlah dan lokasi penempatannya belum dapat dijangkau dengan mudah.

Keempat fasilitas tersebut termasuk prioritas utama yang dibutuhkan pengguna pasar (pedagang maupun pembeli). Fasilitas lain yang bukan prioritas utama bagi pengguna pasar dan tidak dianggap hal yang penting adalah akses bagi pengguna kursi roda, namun kelima fasilitas tersebut merupakan kriteria standar dalam SNI Pasar Rakyat yang harus tersedia dalam Pasar Rakyat Kelas I.

Berdasarkan hasil analisis kepuasan (CSI) pengguna untuk pasar kelas I di Kabupaten Bogor, diperoleh nilai CSI sebesar $73.71 \%$ sehingga dapat disimpulkan bahwa tingkat kepuasan rata-rata pengguna pasar terhadap pasar kelas I yang ada di Kabupaten Bogor ada masuk pada kriteria cause for concern. Hal ini berarti masih perlu dilakukan perbaikan pada fasilitas yang tersedia pada sebagian besar pasar kelas I. 
b) Pasar Kelas II

Analisis kepentingan pada pasar kelas II di Kabupaten Bogor disajikan pada Gambar 6. Dari 27 fasilitas yang dievaluasi, terdapat 21 fasilitas yang masuk kedalam kuadran II, artinya 21 fasilitas tersebut dianggap oleh pengguna pasar sebagai fasilitas yang sangat penting dan kondisinya sudah sesuai dengan kebutuhan pengguna pasar. Selain itu, terdapat lima fasilitas yang masuk ke dalam area kuadran I yaitu fasilitas 6, 7, 8, 21 dan 22. Kelima fasilitas tersebut merupakan prioritas utama bagi pengguna pasar namun kondisi yang ada saat ini masih belum memuaskan bagi pengguna pasar. Diperlukan evaluasi dan koreksi pada fasilitas tersebut agar pasar rakyat dapat berjalan dengan optimal.

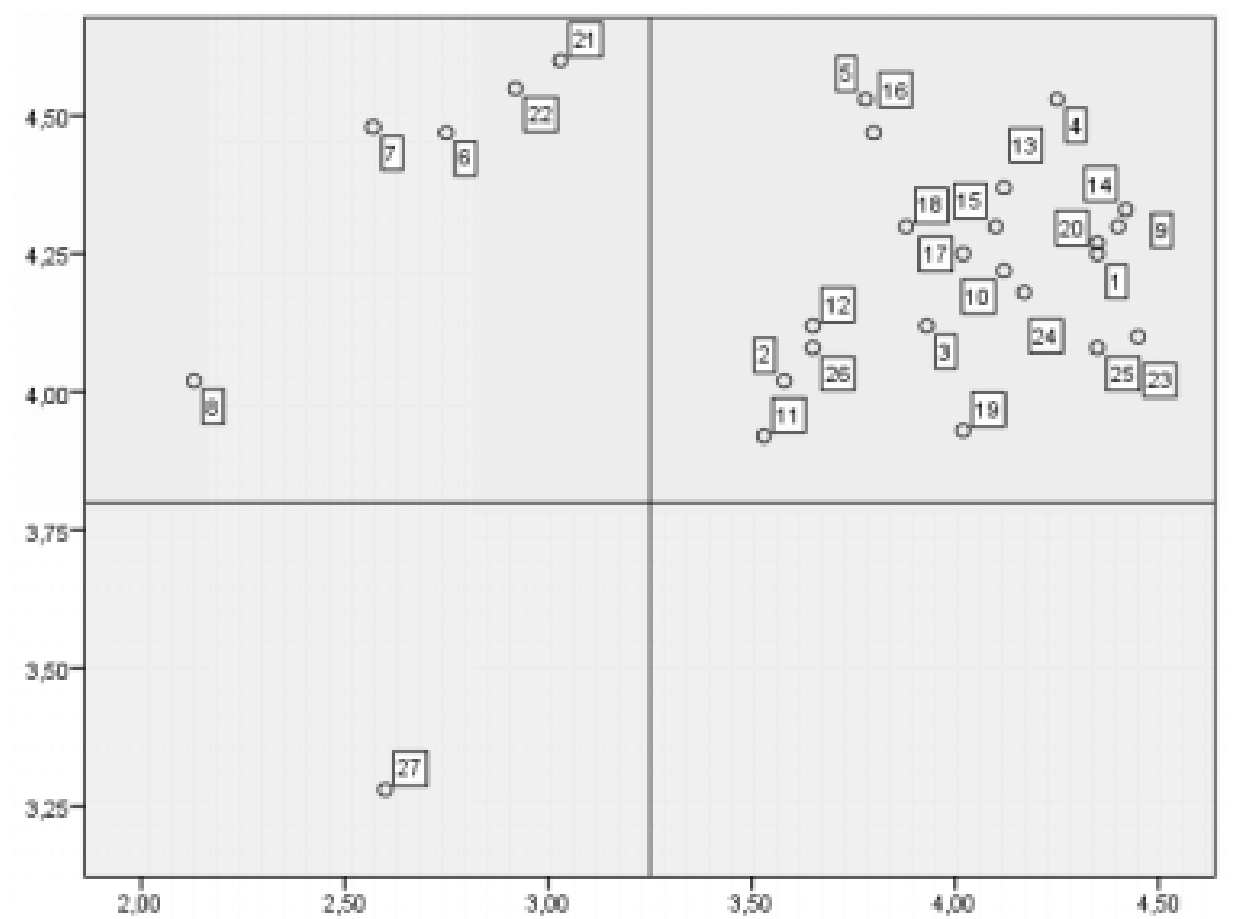

Gambar 6. IPA Pasar Kelas II

Terdapat satu fasilitas yang masuk ke dalam area kuadran III, yang dianggap tidak begitu penting dan kondisinya belum memuaskan pengguna pasar. Dalam hasil survei pasar kelas II di Kabupaten Bogor, tidak ada fasilitas yang masuk dalam kuadran IV, hal ini berarti seluruh fasilitas yang dievaluasi merupakan hal yang dianggap penting bagi pengguna pasar.

Berdasarkan hasil kuadran IPA pasar kelas II, terdapat lima fasilitas yang perlu dilakukan evaluasi dan koreksi yaitu jumlah hidran air, lokasi hidran air, pos ukur ulang, jumlah CCTV, dan lokasi CCTV. Hidran air 
yang merupakan salah satu fasilitas keselamatan terhadap bahaya kebakaran belum tersedia di Pasar Cicangkal dan Pasar Citayam. Pasar Jasinga sudah tersedia hidran air, namun hanya berjumlah satu. Sedangkan di Pasar Cigudeg hidran air yang tersedia berada pada lokasi yang sulit untuk dijangkau.

Fasilitas pos ukur ulang belum tersedia pada seluruh pasar kelas II di Kabupaten Bogor. Hal ini menunjukkan kurangnya perhatian dalam hal perlindungan konsumen pada pasarpasar tersebut, namun bagi pengguna pasar pos ukur ulang merupakan fasilitas kebutuhan yang menjadi prioritas utama. Selain pos ukur ulang, perlindungan bagi rasa aman saat berada di pasar yang merupakan prioritas utama bagi pengguna pasar adalah tersedianya CCTV. Pasar Cigombong dan Pasar Citayam belum menyediakan fasilitas CCTV di dalam area pasar. Sedangkan di pasar kelas II lainnya, pengguna menyatakan bahwa lokasi CCTV belum sesuai dengan kebutuhan pengguna pasar.

Akses bagi pengguna kursi roda bagi pengguna pasar kelas II bukan merupakan prioritas utama dan hanya Pasar Cigudeg yang menyediakan fasilitas tersebut. Namun akses bagi pengguna kursi roda merupakan fasilitas yang menjadi kriteria yang harus tersedia dalam pasar rakyat kelas II berdasarkan SNI Pasar Rakyat.

Berdasarkan hasil analisis kepuasan pengguna pasar terhadap bangunan pasar serta fasilitas yang tersedia di pasar kelas II diperoleh hasil CSI sebesar $74.86 \%$ dan dapat disimpulkan bahwa kepuasan pengguna pasar terhadap pasar kelas II masuk pada kriteria cause for concern. Masih perlu dilakukan perbaikan kondisi fasilitas yang tersedia pada seluruh pasar kelas II.

c) Pasar Kelas III

Hasil yang diperoleh berdasarkan analisis kepentingan untuk tipe pasar kelas III secara umum dapat dilihat pada Gambar 7. Dari 27 fasilitas yang dievaluasi terdapat 17 fasilitas yang masuk ke kuadran II, dalam hal ini pengguna pasar menganggap fasilitas tersebut sangat penting dan kondisinya sudah sesuai dengan kebutuhan pengguna pasar. Sementara itu, terdapat empat fasilitas yang masuk ke dalam area kuadran I yang menurut pengguna pasar masih perlu ditingkatkan kondisinya dan hasil survei ini dapat menjadi bahan evaluasi dan koreksi agar pasar dapat berfungsi secara optimal. 


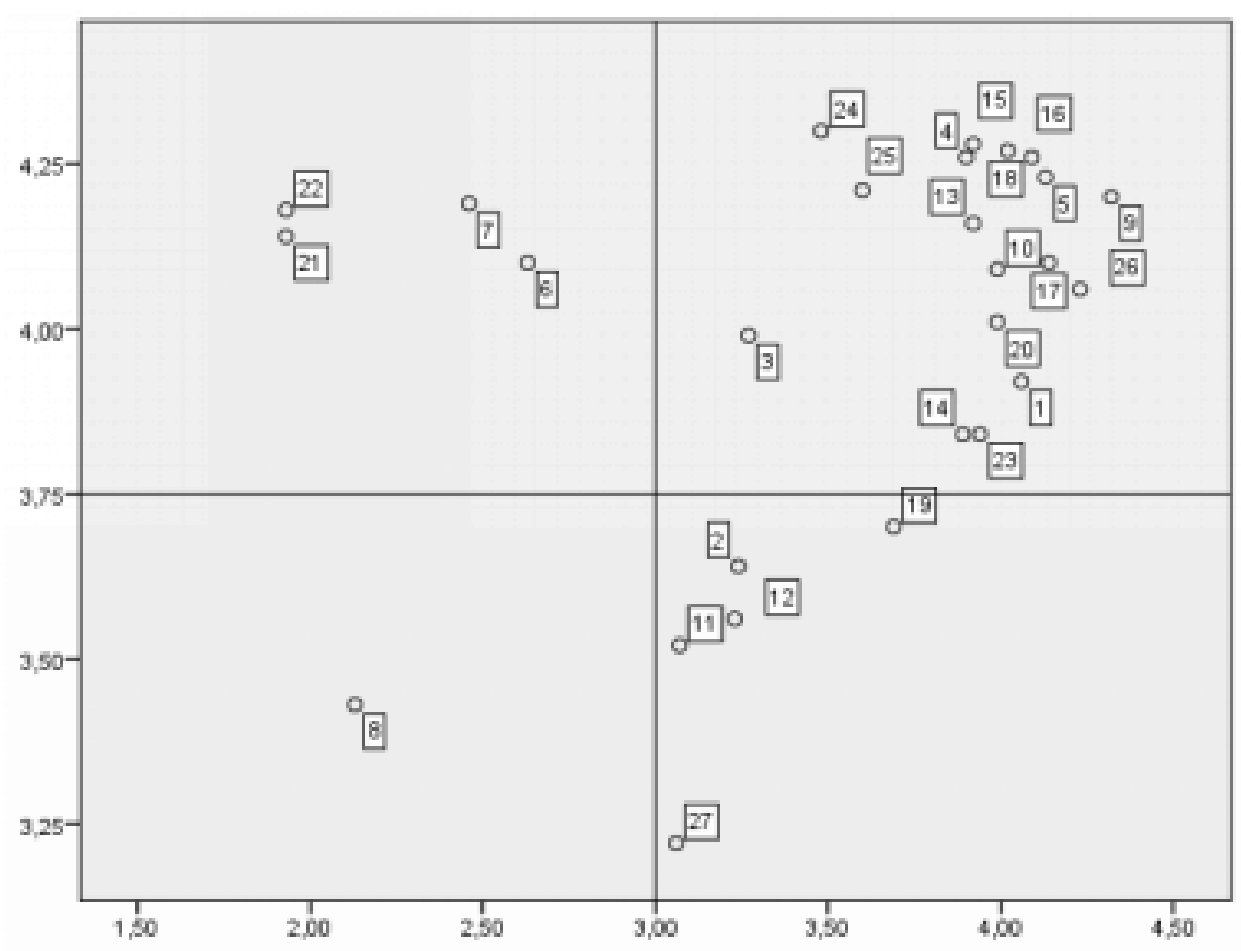

\section{Gambar 7. IPA Pasar Kelas III}

Terdapat satu fasiltas yang masuk ke dalam kuadran III, yang dianggap tidak terlalu penting, dan memang kondisinya belum memuaskan pengguna pasar. Pada pasar kelas III terdapat lima fasilitas yang masuk ke dalam kuadran IV. Hal ini menunjukkan fasilitas tersebut kurang penting bagi pengguna pasar, namun kondisinya sudah baik dan memuaskan pengguna pasar.

Fasilitas sarana prasarana yang tersedia di pasar rakyat kelas III yang merupakan prioritas utama dan kondisinya belum memuaskan pengguna pasar adalah jumlah hidran air, lokasi hidran air, jumlah CCTV dan lokasi CCTV. Fasilitas tersebut merupakan fasilitas yang dianggap pengguna pasar melindungi dari bahaya kebakaran dan memberikan rasa aman dalam bertransaksi di pasar rakyat.

Hidran air hanya tersedia di Pasar Ciseeng dari sembilan pasar yang termasuk pasar kelas III di Kabupaten Bogor. Hal ini menunjukkan bahwa antisipasi kebakaran belum menjadi prioritas utama bagi pasar kelas III, sedangkan pengguna pasar menganggap fasilitas tersebut sebagai prioritas utama yang harus tersedia. Fasilitas keamanan lain yang merupakan prioritas utama dan penting bagi pengguna pasar adalah CCTV. Seluruh pasar kelas III di Kabupaten Bogor belum ada yang dilengkapi 
dengan CCTV, sehingga fasilitas keamanan hanya ditunjang oleh pos keamanan dan petugas yang terbatas.

Fasilitas yang ketersediaanya dianggap tidak begitu penting oleh pengguna pasar adalah pos ukur ulang, dan belum tersedia di seluruh pasar kelas III. Walaupun dianggap tidak begitu penting, namun pos ukur ulang merupakan fasilitas standar yang harus tersedia berdasarkan SNI Pasar Rakyat. Sedangkan fasilitas yang dianggap tidak terlalu penting namun kondisinya sudah memuaskan pengguna pasar adalah ukuran kios/los, jumlah tempat sampah, lokasi tempat sampah, jumlah pos keamanan dan area khusus bagi pengguna kursi roda.

Ukuran kios/los pada pasar kelas III sudah sesuai berdasarkan standar, begitu juga dengan tempat sampah yang tersedia. Walaupun jumlahnya belum sebanding dengan jumlah pedagang, namun pengguna pasar menganggap jumlah dan lokasi peletakan tempat sampah sudah mencukupi kebutuhan mereka. Jumlah pos keamanan pada pasar kelas III juga sudah sesuai dengan SNI Pasar Rakyat. Akses bagi pengguna kursi roda merupakan fasilitas yang tidak dianggap penting oleh pengguna pasar, namun fasilitas ini sudah tersedia pada empat pasar. Walaupun bukan merupakan kebutuhan penting, namun pengguna pasar sudah puas dengan kondisi yang ada saat ini.

Berdasarkan hasil analisis kepuasan pengguna pasar terhadap kondisi fasilitas pasar kelas III yang tersedia saat ini diperoleh nilai CSI sebesar $70.13 \%$ dan masuk pada kriteria poor. Hal ini menunjukkan bahwa di sebagian besar pasar kelas III masih sangat memerlukan perhatian dalam pengelolaan dan perbaikan pada fasilitas yang tersedia di pasar.

Ketidakpuasan pengguna pasar terhadap sarana prasarana yang dianggap sangat penting seperti ketersediaan alat ukur, kebersihan dan keamanan yang tersedia pada pasar rakyat di wilayah Kabupaten Bogor juga ditemui pada beberapa penelitian terdahulu seperti yang dilakukan oleh (Widyanthi, 2013) dimana indikator kepuasan terendah adalah pada kamar kecil yang bersih, lingkungan pasar yang bersih dan penggunaan timbangan yang akurat. Hasil serupa juga ditunjukkan oleh (Minarni \& Nurhadi, 2016) dimana indikator yang masih menjadi prioritas utama dan belum memuaskan antara lain adalah pasar yang bersih dan tidak becek serta toilet 
yang bersih dan tersedianya pos keamanan.

Penelitian (Wijayanto, 2017) juga mengungkapkan ketersediaan alat ukur, tempat sampah dan pemisahan toilet laki-laki dan perempuan juga merupakan aspek yang sangat penting namun kondisinya belum memuaskan. Sedangkan penelitian dari sisi kepuasan pedagang yang dilakukan oleh (Mattanete, 2008) dimana kondisi kebersihan pasar, kondisi MCK dan kondisi tempat usaha juga memiliki hasil indikator kepuasan yang rendah.

\section{KESIMPULAN DAN REKOMENDASI KEBIJAKAN}

Secara keseluruhan, mulai dari Pasar Rakyat Kelas I hingga Pasar Rakyat Kelas III belum ada yang 100\% memenuhi SNI Pasar Rakyat. Hal ini tentu menjadi bahan evaluasi dan saran bagi pengelola pasar agar dapat memperhatikan dan memenuhi standar yang telah ditetapkan sehingga pasar rakyat dapat berfungsi sebagaimana mestinya.

Adapun bagi pengguna pasar rakyat yaitu pedagang dan pembeli, dari 27 fasilitas yang dievaluasi setidaknya ada empat fasilitas yang menjadi perhatian dimana fasilitas tersebut memiliki kepentingan yang tinggi akan tetapi kinerja atau kepuasan yang dirasakan oleh pengguna pasar masih rendah. Keempat fasilitas tersebut antara lain jumlah hidran air, lokasi hidran air, jumlah CCTV, dan lokasi CCTV. Dengan demikian, selayaknya pengelola pasar tidak hanya memerhatikan standar yang telah ditetapkan SNI Pasar Rakyat, tetapi juga persepsi kebutuhan pengguna pasar sehingga aktivitas di pasar rakyat dapat berjalan dengan optimal.

CSI atau indeks tingkat kepuasan pengguna terhadap fasilitas pasar untuk pasar kelas I dan kelas II masuk pada kriteria cause for concern dan pasar kelas III masuk pada kriteria poor. Nilai rata-rata keseluruhan dari ketiga kelas pasar adalah sebesar 70\%, artinya secara umum kondisi pasar rakyat di Kabupaten Bogor masuk pada kriteria poor. Masih diperlukan kebijakan dalam pengelolaan dan perbaikan pada fasilitas yang tersedia di sebagian besar pasar rakyat yang ada di Kabupaten Bogor.

Keterbatasan dalam penelitian ini adalah jumlah responden tiap pasar yang digunakan dalam penelitian ini terbatas, sehingga belum dapat menggambarkan secara rinci kebutuhan pengguna dari pembeli dan pedagang. Oleh sebab itu, disarankan untuk penelitian yang akan datang perlu 
pengambilan responden yang lebih banyak. Selain itu dapat juga dilakukan penelitian fokus pada masing-masing pasar yang ada di wilayah Kabupaten Bogor.

\section{UCAPAN TERIMA KASIH}

Penulis mengucapkan terima kasih kepada Kementerian

Perdagangan, Dinas Perdagangan dan Perindustrian Kabupaten Bogor, Badan Pusat Statistik Kabupaten Bogor, Badan Perencanaan dan Pembangunan

Daerah Kabupaten Bogor, dan PD. Pasar Tohaga yang telah memberikan kemudahan dalam mengakses data yang menunjang penelitian ini. Ucapan terima kasih juga penulis sampaikan kepada Pusbindiklatren Bappenas yang telah mendanai penelitian ini.

\section{DAFTAR PUSTAKA}

Adeliana, V., Ridlo MA., dan Rochani, A. (2017). Evaluasi manajemen pasar tradisional berdasarkan aspek pelayanan prima (studi kasus pasar tradisional Peterongan Semarang). Jurnal Planologi. 14 (2), pp. 175-186.

Adiyadnya, M. S. P., dan Setiawina, N. D. (2015). Analisis Tingkat Efektifitas dan Daya Saing Program Revitalisasi Pasar Tradisional di Pasar Agung Peninjoan Desa Peguyangan Kangin. E-Jurnal EP Unud, Vol. 4 (4), pp. 265281.

Anggraini, L. D., Deoranto, P., dan Ikasari, D. M. (2015). Analisis Persepsi Konsumen Menggunakan Metode Importance Performance Analysis Dan Customer Satifaction Index. Jurnal Industri, Vol. 4 (2), pp. 74-81.
Anggraini, R., dan Susetyo B. (2016). Evaluasi Tingkat Kenyamanan Pada Bangunan Pasar Cipulir. Jurnal Arsitektur, Bangunan \& Lingkungan, Vol. 5 (3), pp.145-162

Dwirahayu, I.A., Marom, A., dan Subowo, A. (2015). Evaluasi Kebijakan Pengaturan Pasar Tradisional "Pasar Bulu" di Kota Semarang. Journal of Public Policy and Management Review, Vol. 4 (3), pp. 1-10.

Handriati, A. A., Sunaryo, dan Helia, V. N. (2015). Analisis Kualitas Pelayanan Publik Terhadap Kepuasan Konsumen dengan Menggunakan Metode SERVPERF-IPA-CSI. Teknoin, Vol. 21 (4), pp. 178-190.

Mattanete, H. (2008). Analisis Kepuasan Pedagang Terhadap Pengelolaan Pasar dan Strategi Pengembangan Pasar. Tesis. Bogor: Sekolah Pascasarjana IPB.

Magdina, T. M., Nasution, M. A., dan Thamrin H. (2018). Evaluasi Kebijakan Revitalisasi Dalam Pengelolaan Pasar Tradisional oleh Perusahaan daerah Kota Medan. Jurnal Antropologi Sosial dan Budaya, Vol. 4 (1), pp. 45-52.

Minarni, E., dan Nurhadi, A. (2016). Analisis Tingkat Kepuasan Pelanggan Terhadap Pelayanan Pasar Tradisional Besuki Tulungagung. Jurnal Benefit, Vol. 3 (1), pp. 45-58.

Nida, M. M. (2014). Evaluasi Kebijakan Revitalisasi Pasar Tradisional di Kota Semarang. Jurnal Pembangunan Wilayah \& Kota, Vol 10 (2), pp. 166174.

Peraturan Daerah Kabupaten Bogor No. 11 Tahun 2012 Tentang Penataan dan Pembinaan Pasar Tradisional, Pusat Perbelanjaan dan Toko Modern. 2012. Bogor.

Peraturan Presiden No. 112 Tahun 2007 Tentang Penataan dan Pembinaan Pasar Tradisional, Pusat Perbelanjaan dan Toko Modern. 2007. Jakarta. 
Peraturan Menteri Dalam Negeri No. 20 Tahun 2012 Tentang Pengelolaan dan Pemberdayaan Pasar Tradisional. 2012. Jakarta.

Peraturan Menteri Perdagangan No. 61/MDAG/PER/8/2015 Tentang Pedoman Pembangunan Pasar. 2015. Jakarta.

Qoriah, C. G. (2014). Model Penataan Pasar Tradisional Berdasarkan Karakteristik Kegiatan, Fasilitas, dan Utilitas, Studi Kasus Pasar Tanjung di Kabupaten Jember. Retrieved from Lembaga Penelitian Universitas Jember. Diunduh tanggal 19 Maret 2019 dari http://repository.unej.ac.id.

Standar Nasional Indonesia 8152:2015 Tentang Pasar Rakyat. 2015. Jakarta.

Stutiari, N. P. E., Arka, S. (2019). Dampak Revitalisasi Pasar Tradisional Terhadap Pendapatan Pedagang dan Tata Kelola Pasar di Kabupaten Badung. E-Jurnal EP Unud, Vol. 8 (1), pp. 148-178.

Sumaga, A. U. (2013). Analisis Kepuasan Pengguna jasa Terhadap Penerapan Manajemen Rekayasa Konstruksi Profesional Ruko Di Kawasan Bussiness Park Kota Gorontalo. Jurnal IImiah Media Engineering, Vol. 3 (1), pp. 6-13.
Triatmojo, M. B., \& Rengga, A. (2019). Evaluasi Program Revitalisasi Pasar Tradisional Rejomulyo di Kota Semarang. Journal of Public Policy and Management Review, Vol 8 (2), pp. 1-13.

Umam, R. K., \& Hariastuti, N. P. (2018). Analisa Kepuasan Pelanggan Dengan Menggunakan Metode Customer Satisfaction Index (CSI) dan Importance Performance Analysis (IPA). Prosiding Seminar Nasional Sains Dan Teknologi Terapan VI, pp. 339-344. Surabaya: Institut Teknologi Adhi Tama Surabaya.

Undang-Undang No 7 Tahun 2014 Tentang Perdagangan. 2014. Jakarta.

Undang-Undang Nomor 8 Tahun 1999 tentang Perlindungan Konsumen. Jakarta.

Widyanthi, N. L. A. M. (2013). Analisis tingkat kepuasan konsumen pasar Agung denpasar. Jurnal Ekonomi Dan Bisnis Universitas Udayana, Vol. 2 (10), pp. 108-126.

Wijayanto, E. (2017). Kualitas pelayanan dan kepuasan pengguna pasar Pemalang Kabupaten Pemalang. Jurnal Pembangunan Wilayah \& Kota, Vol. 13 (1), pp. 44-55. 